\title{
АКТУАЛЬНЫЕ ПРОБЛЕМЫ АДМИНИСТРАТИВНОЙ ОТВЕТСТВЕННОСТИ В СФЕРЕ МИГРАЦИОННЫХ ОТНОШЕНИЙ
}

\begin{abstract}
Аннотация. Предмет статьи состоит в том, что в ней рассматривается, вопросы административной ответственности за нарушение правил пребывания в Российской Федерации иностранных граждан. В статье отмечается, что проблема миграции является остро актуальной для современной России. Для обеспечения режима законности в срере миграционных отношений широко применяются меры административного принуждения и, в частности, меры административной ответственности. Правоприменительная практика выявила проблему различных подходов к привлечению к административной ответственности российских граждан, супругами которых являются иностранные граждане (статья 18.9 «Нарушение иностранным гражданином или лицом без гражданства правил въезда в Российскую Федерацию либо режима пребывания (проживания) в Российской Федерации» КоАП РФ), и российских граждан, супругами которых являются граждане Российской Федерации (статья 19.15.1 «Проживание гражданина Российской Федерации по месту пребывания или по месту жительства в жилом помещении без регистрации» КоАП РФ). Данное различие носит дискриминачионный характер, противоречит нормам Международного пакта о гражданских и политических правах и Семейного кодекса Российской Федерации. Законодателю необходимо принять меры по его оперативному устранению. Методологическую основу статьи составили современные достижения теории познания. В процессе исследования применялись общефилософрский, теоретический, общефилософские методы (диалектика, системный метод, анализ, синтез, аналогия, дедукиия, наблюдение, моделирование), традиционно правовые методы (формально-логический), а также методы, используемые в конкретно-социологических исследованиях (статистические, экспертные оценки и др.). Важный вывод, который сделан по итогам исследования, состоит в том, что в настоящее время необходимо совершенствовать правовые и организационные основы реализации мер административной ответственности в сфрере регулирования миграционных отношений. Основным вкладом, который сделан автором в настоящей статье это необходимость повышение качества реализации миграционной политики в Российской Федерации.
\end{abstract}

Ключевые слова: миграция, выдворение, депортация, наказание, ответственность, миграционная политика, проблема, иностранеи, принуждение, правило.

Abstract. The article considers the issues of administrative responsibility for the violation of the rules of stay in the Russian Federation for foreign citizens. The author notes that the problem of migration is very significant in modern Russia. To ensure law and order in the sphere of migration, the measures of administrative coercion are widely used, particularly, the measures of administrative responsibility. Law enforcement practice has revealed the problem of existence of various approaches to the imposition of administrative responsibility on Russian citizens, married to foreign citizens (article 18.9 "Violation of entry regulations or rules of stay in the Russian Federation by a foreign citizen or a stateless person" of the Administrative Offences Code of the Russian Federation), and Russian citizens, married to Russian citizens (article 19.15.1."Residence of a citizen of the Russian Federation at a place of stay or a place of residence without a registration" of the Administrative Offences Code of the Russian Federation). This difference is of a discriminatory nature; it contradicts the provisions of the International Covenant on Civil and Political Rights and the Family Code of the Russian Federation. The legislator should make efforts to eliminate this difference. The research methodology is based on the recent achievements in epistemology. The author applies general philosophical and theoretical methods (dialectics, the system method, analysis, synthesis, analogy, deduction, observation and modeling), traditional methods of jurisprudence (formal-logical) and the special methods of sociology (statistical methods, expert assessments, etc.). The author concludes that at present, 


\section{Административное и муниципальное право 10 (106) • 2016}

it is necessary to improve legal and organizational grounds of realization of administrative responsibility measures in the sphere of migration. The author concludes about the necessity to improve the quality of migration policy implementation in the Russian Federation.

Key words: migration policy, responsibility, punishment, deportation, exclusion, migration, problem, foreign citizen, coercion, rule.

$\Pi$

роблема миграции остро стоит в современной России и не только. Это общемировая тенденция, которая в обозримой перспективе будет и дальше нарастать. Задача правового демократического государства состоит в том, чтобы упорядочить миграционные потоки, направить их в правовое русло. Если миграционные процессы носят во многом стихийный, неуправляемый характер, уровень обеспечения безопасности государств резко снижается, кроме того, неконтролируемая миграция не позволяет обеспечить защиту прав самих мигрантов [1]. Словом, государству необходимо сделать миграцию цивилизованной, тем более, что наряду с негативными моментами, а это, прежде всего, ухудшение криминогенной обстановки и рост межнациональной напряженности, есть у нее и весомая позитивная составляющая. Нужно признать, что миграция способна стать фактором, благотворно влияющим на рынок труда. Дело в том, что во многих сегментах отечественной экономики остро ощущается недостаток трудовых ресурсов, восполнить который в определенной мере позволяет миграция. Как известно, в России велика смертность людей трудоспособного возраста. Так, по данным Уполномоченного по правам человека Российской Федерации в 2015 г. число умерших в России от всех причин составило 1911413 человек, из них 458218 (23,97 $\%$ от общего числа умерших!) ушли из жизни в трудоспособном возрасте [2]. Кроме того, немало профессий, которые в силу различных причин, главным образом, из-за невысокого уровня оплаты труда, для российских граждан не привлекательны. Напротив, эти профессии оказываются востребованы со стороны мигрантов, прежде всего тех, кто приезжает из республик бывшего СССР, где имеет место избыток трудовых ресурсов, а уровень жизни основной массы населения значительно ниже чем в России.

Проблема миграции находится в центре внимания политического руководства страны. Выступая 15 марта 2016 г. на расширенном заседании коллегии МВД России, Президент Российской Федерации отметил, что ситуация с незаконной миграцией требует серьезного внимания. У нас миллионы мигрантов, прежде всего, конечно, из республик бывшего Советского Союза. Нужно сделать все, подчеркнул Глава государства, чтобы они жили в нормальных условиях, трудились там, где их берут на работу, чтобы они исполняли закон Российской Федерации. Важным шагом, направленным на совершенствование государственного управления в сфере миграции, стало упразднение указом Президента Российской Федерации от 6 апреля 2016 года № 156 Федеральной миграционной службы (ФМС), функции которой, а также сокращенная на $30 \%$ штатная численность были переданы МВД России. В структуре центрального аппарата МВД России образовано Главное управление по вопросам миграции. На должность начальника этого подразделения, а должность это генеральская, указом Президента Российской Федерации от 13 апреля 2016 года № 183 была назначена полковник внутренней службы O.Е. Кириллова, ранее возглавлявшая Управление ФМС по городу Москве. Данный шаг в современных условиях представляется своевременным и во всех отношениях вполне оправданным. Он свидетельствует об усилении административных начал в сфере регулирования миграционных отношений, основанных на методе принуждения, прежде всего принуждения административного, который традиционно используют в своей деятельности органы внутренних дел. Правда, возникает резонный вопрос: стоило ли в 2004 году, в ходе административной реформы, принимать решение о выделении ФМС в качестве самостоятельного органа исполнительной из системы того же МВД России, чтобы через двенадцать лет упразднить службу, вернув ее функции в МВД России? Приходится признать, что подобные решения принимались уже не раз, и, вероятнее всего, будут приниматься и впредь.

Реальность законных интересов государства, прав и свобод мигрантов, управляемость миграционными процессами возможны только в условиях надлежащего правового порядка. Его защита - одна из задач права. Эффективная борьба с правонарушениями возможна только при наличии воспитательного механизма, заключающегося в установлении обязанности претерпеть негативные последствия неправомерного поведения, т.е. при наличии ответственности [3]. И действительно, для обеспечения правопорядка в сфере миграционных отношений широко применяется административное принуждение, весь широчайший спектр его мер, предусмотренных законом, в частности, административная ответственность, которая, можно без преувеличения сказать, является основным видом 
юридической ответственности в сфере миграционных отношений, имеет весьма репрессивный характер, который в последние годы, во многом по объективным причинам (прежде всего, рост числа незаконных мигрантов), значительно ужесточился. Хотелось бы специально подчеркнуть: административная ответственность - неотъемлемый элемент государственного регулирования миграционных отношений.

Следует сказать, что правоприменительная практика регулярно выявляет, на первый взгляд не всегда заметные, проблемы административной ответственности. Сфера миграционных отношений в данном случае исключением не является. На одной из таких проблем хотелось бы остановиться подробнее, тем более что она привлекла внимание Уполномоченного по правам человека Российской Федерации и ждет своего скорейшего разрешения.

Как известно, статус иностранных граждан в Российской Федерации определяется Федеральным законом от 25 июля 2002 г. № 115-Ф3 «0 правовом положении иностранных граждан в Российской Федерации». Данный нормативный правовой акт предусматривает миграционный учет иностранных граждан, который осуществляется на основании Федерального закона от 18 июля 2006 г. № 109-Ф3 «О миграционном учете иностранных граждан и лиц без гражданства» и Правил осуществления миграционного учета, утвержденных Постановлением Правительства Российской Федерации от 15 января 2007 г. № 9. Находясь в Российской Федерации, иностранные граждане должны соблюдать установленные для них правила пребывания в стране. Законодательство предусматривает обязанность иностранного гражданина встать на миграционный учет и зарегистрироваться. Предусмотрены учет по месту пребывания и регистрационный учет по месту жительства. Исполнение данной обязанности обеспечивается мерами административной ответственности, которые применяются не только к собственно иностранным гражданам, но и к гражданам Российской Федерации, которые так или иначе являются участниками миграционных отношений.

Так, статья 18.9. КоАП РФ предусматривает административную ответственность за нарушение правил пребывания в Российской Федерации иностранных граждан и лиц без гражданства. В частности, часть 3 данной статьи предусматривает административную ответственность за предоставление жилого помещения иностранному гражданину или лицу без гражданства, находящимся в Российской Федерации с нарушением установленного порядка или правил транзитного проезда через ее территории. Анализ и оценка в совокупности норм статьи 18.9. КоАП позволяет сделать вывод, что она относится только к тем отношениям между иностранными гражданами и лицами без гражданства и их российскими контрагентами, которые не основаны на узах родства (свойства), а носят деловой характер (служебные или частные дела). Не случайно поэтому, что в тексте статьи используются такие термины как «приглашающая сторона» и «принимающая сторона».

В части 2 статьи 3 Закона Российской Федерации от 25 июня1993 г. № 5242-I «0 праве граждан Российской Федерации на свободу передвижения, выбор места пребывания и жительства в Российской Федерации» установлена обязанность гражданина Российской Федерации регистрироваться по месту пребывания и по месту жительства в пределах Российской Федерации. Правила регистрации утверждены постановлением Правительства Российской Федерации от 17 июля 1995 г. № 713. Применительно к российским гражданам исполнение обязанности регистрироваться также, как и в отношении граждан иностранных, обеспечивается мерами административной ответственности. Часть 1 статьи 19.15.1. КоАП РФ предусматривает административную ответственность гражданина Российской Федерации за проживание по месту пребывания или по месту жительства в жилом помещении без регистрации либо допущение такого проживания нанимателем или собственником этого жилого помещения свыше установленных законом сроков.

В Примечании к статье 19.15.1 КоАП РФ говорится, что граждане Российской Федерации освобождаются от административной ответственности по данной статье, в частности, если проживающие совместно с нанимателем или собственником жилого помещения лица являются по отношению к нему супругами, т.е. свойственниками или родственниками по закону.

Конституция Российской Федерации (часть 3 статьи 62) предусматривает, что иностранные граждане и лица без гражданства пользуются в Российской Федерации правами и несут обязанности наравне с гражданами Российской Федерации, кроме случаев, установленных федеральным законом или международным договором Российской Федерации. Близкие по содержанию нормы содержатся и в Федеральном законе от 25 июля 2002 г. № 115-Ф3 «О правовом положении иностранных граждан в Российской Федерации», статья 4 которого гласит: иностранные граждане пользуются в Российской Федерации правами и несут обязанности наравне с гражданами Российской Федерации, за исключением случаев, предусмотренных законом. 


\section{Административное и муниципальное право 10 (106) 2016}

Как видно, законодатель, признавая равенство прав граждан Российской Федерации и иностранных граждан, тем не менее эти права не отождествляет, но предусматривает, исключения, которые устанавливаются нормативно, а именно либо федеральным законом, либо международным договором. При этом по общему правилу законодатель не предусматривает разных подходов к установлению той же административной ответственности применительно к гражданам Российской Федерации.

Таким образом, граждане Российской Федерации, супругами которых являются иностранные граждане, и граждане Российской Федерации, супругами которых являются российские граждане, оказываются в неравном положении применительно к привлечению их к административной ответственности. Гражданство супруга в данном случае является основанием для различных подходов при решении законодателем вопроса об освобождении гражданина Российской Федерации от административной ответственности. Если супруг - гражданин Российской Федерации, то лицо освобождается от данной ответственности, если иностранный гражданин - привлекается по части 3 статьи 18.9 КоАП РФ.

Подобный подход, как представляется, противоречит статье 26 Международного пакта о гражданских и политических правах и частям 1 и 2 Конституции Российской Федерации. В статье 26 Пакта установлено, что все люди равны перед законом и имеют право без всякой дискриминации на равную защиту закона. В этом отношении всякого рода дискриминация должна быть запрещена законом и закон должен гарантировать всем лицам равную и эффективную защиту против дискриминации по какому бы то ни было принципу как-то расы, цвета кожи, пола, языка, религии, политических или иных убеждений, национального или социального происхождения, имущественного положения, рождения или иного обстоятельства. В частях 1 и 2 Конституции Российской Федерации также устанавливается равенство всех перед законом и судом, указывается, что государство гарантирует равенство прав и свобод человека и гражданина независимо от пола, расы, национальности, языка, происхождения, имущества и должностного положения, места жительства, отношения к религии, убеждений, принадлежности к общественным объединениям, а также других обстоятельств. Именно гражданство супруга в данном случае и должно рассматриваться в качестве иного (другого) обстоятельства, на основании которого имеет место дискриминация, а любые формы дискриминации, как известно, запрещены.
Согласно ст. 19.15.1. КоАП РФ если наниматель или собственник жилого помещения предоставил жилое помещение гражданину Российской Федерации, являющемуся по отношению к нему супругом, то он освобождается от административной ответственности за правонарушение, предусмотренное данной статьей. В данном случае, основание для освобождения от ответственности является не только наличие определенной степени родства (свойства) между тем кто предоставляет жилое помещение и тем, кому оно предоставляется, но и наличие у последнего, а именно супруга нанимателя или собственника жилого помещения, гражданства Российской Федерации. Граждане Российской Федерации - супруги иностранных граждан и граждане Российской Федерации - супруги российских граждан оказываются, таким образом, в неравных условиях.

Международный пакт о гражданских и политических правах (часть 1 статьи 23) определяет, что семья является естественной и основной ячейкой общества и имеет право на защиту со стороны общества и государства. В Семейном кодексе Российской Федерации (часть 1 статьи 31 «Равенство супругов») устанавливается, что каждый из супругов свободен в выборе рода занятий, профессии, мест пребывания и жительства. Семейные отношения вполне естественно предполагают совместное проживание супругов, без каких-либо внешних ограничений со стороны государства. Действующая редакция части 3 статьи 18.9 КоАП РФ содержит дискриминационные нормы, а потому должна быть скорректирована.

Представляется целесообразным привлечь внимание законодателя к обозначенной проблеме. В часть 3 статьи 18.9 КоАП РФ следует внести изменение, которое позволило бы освободить от административной ответственности российских супругов иностранных граждан за предоставление ими жилого помещения своим супругам-иностранцам. Тем самым российские граждане, являющиеся супругами иностранных граждан, будут уравнены в праве на освобождение от административной ответственности с российскими гражданами, чьи супруги - граждане Российской Федерации.

В заключении хотелось бы отметить, что поводом к написанию данной работы, тема которой не входит в круг традиционных научных интересов автора настоящей статьи, послужило обращение аппарата Уполномоченного по правам человека в Российской Федерации от 29 июня 2016 г. № ВБ19467-431 в Институт государства и права Российской академии наук, в котором высказывалась просьба подготовить заключение по обозначенной проблеме. В ходе его подготовки и возникла идея написать эту небольшую работу. 
Библиография:

1. Семенова А.В. Современное состояние миграционной безопасности в Российской Федерации // Административное право и процесс. 2016. № 2. С. 40.

2. Доклад уполномоченного по правам человека в Российской Федерации за 2015 год // Российская газета. 2015.24 марта.

3. Хабриева Т.Я. Миграционное право России: теория и практика. М.: Юридическая фирма «КОНТРАКТ». 2008. С. 180.

4. Сизов И.Ю. Проблемы информационного обеспечения деятельности органов внутренних дел при противодействии миграционной преступности // Полицейская деятельность. 2012. №1. С. 26-30.

5. Вострокнутова О.Ю. К вопросу о совершенствовании административно-правового регулирования миграционной политики Российской Федерации // Полицейская деятельность. 2011. № 1. С. 38-41.

6. Агапов А.Б. К вопросу о публичном принуждение в российском праве // NB: Административное право и практика администрирования. 2013. № 7. C. 58-87. DOI: 10.7256/2306-9945.2013.7.9922. URL: http://www.e-notabene.ru/ al/article_9922.html

7. Терентьева Г.В. Новый Глобальный подход ЕС к миграции и мобильности (GAMM) и социальные аспекты миграционной политики Италии // Политика и Общество. 2013. № 4. C. 472-478. DOI: 10.7256/1812-8696.2013.04.12.

8. Терентьева Г.В. Новый Глобальный подход ЕС к миграции и мобильности (GAMM) и социальные аспекты миграционной политики Италии // Тренды и управление. 2013. № 3. C. 62-71. DOI: 10.7256/2307-9118.2013.3.6592.

9. Церунян В.А. Противодействие преступности мигрантов в России // Полицейская деятельность. 2016. № 1. C. 26 - 32. DOI: 10.7256/2222-1964.2016.1.17846.

10. Леденева В.Ю. «Правовые и организационные основы противодействия незаконной миграции» // Право и политика. 2015. № 7. C. 945 - 953. DOI: 10.7256/1811-9018.2015.7.10781.

11. Другов Я.А. Кодекс Иркутской области об административных правонарушениях: как возможный результат систематизации законодательства об административной ответственности // Право и политика. 2016 . № 2 . C. 204 - 208. DOI: 10.7256/1811-9018.2016.2.17951.

\section{References (transliterated):}

1. Semenova A.V. Sovremennoe sostoyanie migratsionnoi bezopasnosti v Rossiiskoi Federatsii // Administrativnoe pravo i protsess. 2016. № 2. S. 40.

2. Doklad upolnomochennogo po pravam cheloveka v Rossiiskoi Federatsii za 2015 god // Rossiiskaya gazeta. 2015. 24 marta.

3. Khabrieva T.Ya. Migratsionnoe pravo Rossii: teoriya i praktika. M.: Yuridicheskaya firma «KONTRAKT». 2008. S. 180.

4. Sizov I.Yu. Problemy informatsionnogo obespecheniya deyatel'nosti organov vnutrennikh del pri protivodeistvii migratsionnoi prestupnosti // Politseiskaya deyatel'nost'. 2012. № 1. C. 26-30.

5. Vostroknutova O.Yu. K voprosu o sovershenstvovanii administrativno-pravovogo regulirovaniya migratsionnoi politiki Rossiiskoi Federatsii // Politseiskaya deyatel'nost'. 2011. № 1. C. 38-41.

6. Agapov A.B. K voprosu o publichnom prinuzhdenie v rossiiskom prave // NB: Administrativnoe pravo i praktika administrirovaniya. 2013. № 7. C. 58-87. DOI: 10.7256/2306-9945.2013.7.9922. URL: http://www.e-notabene.ru/al/ article_9922.html

7. Terent'eva G.V. Novyi Global'nyi podkhod ES k migratsii i mobil'nosti (GAMM) i sotsial'nye aspekty migratsionnoi politiki Italii // Politika i Obshchestvo. 2013. № 4. C. 472-478. DOI: 10.7256/1812-8696.2013.04.12.

8. Terent'eva G.V. Novyi Global'nyi podkhod ES k migratsii i mobil'nosti (GAMM) i sotsial'nye aspekty migratsionnoi politiki Italii // Trendy i upravlenie. 2013. № 3. C. 62-71. DOI: 10.7256/2307-9118.2013.3.6592.

9. Tserunyan V.A. Protivodeistvie prestupnosti migrantov v Rossii // Politseiskaya deyatel'nost'. 2016. № 1. C. 26 - 32. DOI: 10.7256/2222-1964.2016.1.17846.

10. Ledeneva V.Yu. «Pravovye i organizatsionnye osnovy protivodeistviya nezakonnoi migratsii» // Pravo i politika. 2015. № 7. C. 945 - 953. DOI: 10.7256/1811-9018.2015.7.10781.

11. Drugov Ya.A. Kodeks Irkutskoi oblasti ob administrativnykh pravonarusheniyakh: kak vozmozhnyi rezul'tat sistematizatsii zakonodatel'stva ob administrativnoi otvetstvennosti // Pravo i politika. 2016. № 2. C. 204 - 208. DOI: 10.7256/18119018.2016.2.17951. 